\title{
IRS1 degradation and increased serine phosphorylation cannot predict the degree of metabolic insulin resistance induced by oxidative stress
}

\author{
R. Potashnik ${ }^{1}$, A. Bloch-Damti ${ }^{1}$, N. Bashan ${ }^{1}$, A. Rudich ${ }^{1,3}$ \\ ${ }^{1}$ Department of Clinical Biochemistry, Ben-Gurion University of the Negev, Beer-Sheva, Israel \\ 3 The S. Daniel Abraham Center for Health and Nutrition, Ben-Gurion University of the Negev, Beer-Sheva, Israel
}

\begin{abstract}
Aim/hypothesis. Oxidative stress was shown to selectively induce impaired metabolic response to insulin, raising the possible involvement of alterations in Insulin-Receptor-Substrate (IRS) proteins. This study was conducted to assess whether oxidative stress induced IRS protein degradation and enhanced serine phosphorylation, and to assess their functional importance. Methods. 3T3-L1 adipocytes and rat hepatoma cells (FAO) were exposed to micro-molar $\mathrm{H}_{2} \mathrm{O}_{2}$ by adding glucose oxidase to the culture medium, and IRS1 content, its serine phosphorylation and downstream metabolic insulin effects were measured.

Results. Cells exposed to oxidative stress exhibited decreased IRS1 (but not IRS2) content, and increased serine phosphorylation of both proteins. Total protein ubiquitination was increased in oxidized cells, but not in cells exposed to prolonged insulin treatment. Yet, lactacystin and MG132, two unrelated proteasome inhibitors, prevented IRS1 degradation induced by pro-
\end{abstract}

longed insulin but not by oxidative stress. The PI 3-kinase inhibitor LY294002 and the mTOR inhibitor rapamycin, but not the MEK1 inhibitor PD98059, could prevent IRS1 changes in oxidized cells. Rapamycin, which protected against IRS1 degradation and serine phosphorylation was not associated with improved response to acute insulin stimulation. Moreover, the antioxidant alpha lipoic acid, while protecting against oxidative stress-induced insulin resistance in 3T3-L1 adipocytes, could not prevent IRS1 degradation and serine phosphorylation.

Conclusion/interpretation. Oxidative stress induces serine phosphorylation of IRS1 and increases its degradation by a proteasome-independent pathway; yet, these changes do not correlate with the induction of impaired metabolic response to insulin. [Diabetologia (2003) 46:639-648]

Keywords IRS1 degradation, oxidative stress, $\mathrm{H}_{2} \mathrm{O}_{2}$, insulin resistance, serine-phosphorylation, lipoic acid, ubiquitination.
Received: 8 October 2002 / Revised: 20 December 2002

Published online: 15 May 2003

(C) Springer-Verlag 2003

Corresponding author: N. Bashan PhD, Department of Clinical Biochemistry, Faculty of Health Sciences, Ben-Gurion University of the Negev, 84103 Beer-Sheva, Israel

E-mail: nava@bgumail.bgu.ac.il

Abbreviations: PI3-kinase, phosphatidylinositol 3'-kinase; mTOR, mammalian target of rapamycin; MEK1, mitogen activated protein kinase1; SH2, Src homology 2; $\mathrm{PKB}$, protein kinase $\mathrm{B}$; $\mathrm{PKC}$, protein kinase $\mathrm{C}$; ERK, extracellular signalregulated kinase; GSK3, glycogen synthase kinase-3; JNK, c-Jun N-terminal kinase; PAGE, polyacrylamide gel electrophoresis; PDGF, platelet derived growth factor.
Oxidative stress has been shown in recent years to represent a causative factor for insulin resistance in cells in culture $[1,2,3]$, and to accompany diabetes and insulin resistance states [4]. Cells exposed to oxidative stress show complex changes in protein function, localization, as well as in gene regulation $[5,6,7]$. Despite this diversity of cellular changes and the large number of proteins involved, specificity to the insulin signalling cascade had been suggested, since PDGF signalling and metabolic effects under the same conditions were unaltered in 3T3-L1 adipocytes [2]. One potential source for such specificity is the changes that Insulin Receptor Substrate (IRS) proteins undergo following oxidative stress, since these proteins are involved in insulin but 
not in PDGF signalling. Previous studies suggested that oxidative stress alters insulin-mediated re-localization of IRS1 [7], but whether oxidative stress directly alters IRS proteins and what is the functional significance of these alterations is unknown.

The IRSs constitute one family of substrate proteins for the tyrosine kinase activity of the insulin receptor (and closely related receptors) [8]. Their tyrosine phosphorylation promotes their participation in transmitting the insulin signal, by inducing their interactions with protein-containing $\mathrm{SH} 2$ domain(s), like the p85 sub-unit of PI 3-kinase [9]. Cellular models for insulin resistance and in vivo studies suggested an association between insulin resistance and alterations in IRS proteins, and particular in IRS1 and IRS2 [10, $11,12,13]$. A reduction in IRS1 expression has been reported in isolated adipocytes from insulin-resistant patients and Type 2 diabetic patients [10, 11], but not in skeletal muscle $[12,13]$. Decreased IRS1 protein content was reported in cells in culture exposed to various inducers of insulin resistance, including TNF$\alpha$ and chronic insulin $[14,15,16]$. Recent data suggests that prolonged exposure to insulin and TNF- $\alpha$ could result in increased degradation of IRS1 by the ubiquitin-proteasome system [17, 18, 19]. Conflicting reports are currently available regarding the involvement of the proteasome in determining IRS2 content under the same conditions $[17,19,20]$. Such an increase in proteasomal degradation of IRS1 is an attractive mechanism for insulin resistance, since increased ubiquitination of proteins is a common cellular mechanism for down-regulating various signalling processes [21].

In addition to decreased protein content of IRSs, increased phosphorylation of IRS proteins on serine/threonin residues has been reported as an additional alteration that accompanies the insulin-resistant state [22]. The primary sequence of IRS1 and IRS2 includes over 30 potential phosphorylation sites on serine and threonin residues, which could be the substrates for various kinases based on both the kinases' recognition motifs and on in vitro and in vivo assays. These include kinases like PKB and PKCs [23, 24], ERK1/2 [25], GSK3 [26], JNK [27], as well as the serine kinase activity of the p110 sub-unit of PI 3-kinase [28]. Some of these kinases were implicated in down-regulating the insulin signal, based on their activation by various inducers of insulin resistance. Moreover, some [29], (but not all [23]) of the phosphoserine residues might impair insulin receptor-mediated phosphorylation on adjacent tyrosine residues of IRS, resulting in impaired early insulin signalling events. Recently it was suggested that increased serine phosphorylation on specific sites on IRS1 proceeds its degradation $[18,30,31]$.

The aim of this study was to evaluate the effect of oxidative stress on IRS1 protein content and its serine phosphorylation state, in relation to the induction of cellular insulin resistance. Our findings suggest that oxidative stress induces the serine phosphorylation of IRSs and the protein degradation of IRS1 in a LY294002 and rapamycin-sensitive, but lactacystinresistant process. Yet, these IRS changes do not necessarily correlate with the induction of impaired metabolic actions of insulin.

\section{Materials and methods}

Chemicals. Tissue culture medium, serum and antibiotic solutions were obtained from Biological Industries (Beit-Haeemek, Israel). Recombinant human insulin was from Novo Nordisk (Bagsvaerd, Denmark). Polyclonal IRS1 antibodies (C-terminus), anti p85 and anti IRS2 were obtained from Upstate Biotechnology (Lake Placid, N.Y., USA). Alpha racemic lipoic acid was kindly provided by ASTA medica (Frankfurt, Germany). Phosphoserine antibodies were obtained from Chemicom International (Temecula, Calif., USA). Lactacystin and MG132 were purchased from Calbiochem (San Diego, Calif., USA). Alkaline phosphatase and all other chemicals were obtained from Sigma Chemical (St. Louis, Mo., USA).

Cell culture and treatment. 3T3-L1 pre-adipocytes (American Type Culture Collection) were grown to confluence in Dulbeco's Modified Eagle's Medium (DMEM) containing $25 \mathrm{mmol} / \mathrm{l} \mathrm{glu-}$ cose, exactly as previously described [1]. Cells were used 11 to 12 days following differentiation induction when showing a greater than $90 \%$ adipocyte phenotype. Rat hepatoma Fao cells were grown to confluence in RPMI medium containing $5 \mathrm{mmol} / \mathrm{l}$ glucose with $10 \%$ foetal calf serum. Cells were serum deprived for $16 \mathrm{~h}$ by incubation in medium supplemented with $0.5 \%$ radioimmunoassay grade bovine serum albumin (BSA), with or without pre-treatment reagents. Cells were then rinsed three times in PBS, and exposed to fresh medium with or without glucose oxidase [type II from Aspergillus niger, 20000 unit/g solid in nonoxygen saturated conditions, Sigma Chemical (St Louis, Mo.)], or with $100 \mathrm{nmol} / \mathrm{l}$ insulin.

Cell lysates and Western blot analysis. Lysates for immunoblots were prepared in a lysis buffer containing $50 \mathrm{mmol} / \mathrm{l}$ Tris- $\mathrm{HCl}$ $\mathrm{pH} 7.5,0.1 \%$ (w/v) Triton X-100, $1 \mathrm{mmol} / \mathrm{l}$ EDTA, $1 \mathrm{mmol} / \mathrm{l}$ EGTA, $1 \mathrm{mmol} / \mathrm{l}$ sodium orthovanadate, $50 \mathrm{mmol} / \mathrm{l} \mathrm{NaF}$, $10 \mathrm{mmol} / \mathrm{l}$ sodium $\beta$-glycerophosphate, $5 \mathrm{mmol} / \mathrm{l}$ sodium pyrophosphate, $0.1 \%$ (v/v) 2-mercaptoethanol, and protease inhibitors [a 1:1000 dilution of protease inhibitor cocktail (Sigma $\mathrm{P}-8340)]$. Lysates were collected, gently shaken for $20 \mathrm{~min}$. at $4^{\circ} \mathrm{C}$, centrifuged $\left(12000 \mathrm{~g}, 15 \mathrm{~min}, 4^{\circ} \mathrm{C}\right)$, and the supernatant fraction was collected. Protein concentration was assessed using Bio-Rad reagents (Bio-Rad Laboratories, Munchen, Germany). Aliquots of 30-75 $\mu$ g protein were resolved on $7.5 \%$ SDSPAGE and subjected to Western blots followed by quantitation by video densitometry analysis [7].

$\mathrm{H}_{2} \mathrm{O}_{2}$ determination. $\mathrm{H}_{2} \mathrm{O}_{2}$ generated by glucose oxidase was measured by a colorimetric method based on production of ferrithiocyanate [32]. One $\mathrm{ml}$ aliquots of medium were collected and $0.1 \mathrm{ml} \mathrm{TCA}(50 \% \mathrm{w} / \mathrm{v})$ was added. The samples were centrifuged at $10000 \mathrm{~g}$ for $3 \mathrm{~min}, 0.2 \mathrm{ml}$ of $10 \mathrm{mmol} / \mathrm{l}$ ferrous ammonium sulfate and $0.1 \mathrm{ml}$ of $2.5 \mathrm{~mol} / \mathrm{l}$ sodium thiocyanate were added to the supernatant. Absorption of the ferrithiocyanate complex was measured using a spectrophotometer at $480 \mathrm{~nm}$, and compared to standard curves obtained from dilutions of a standard $\mathrm{H}_{2} \mathrm{O}_{2}$ solution. 
Treatment with alkaline phosphatase. Lysates for alkaline phosphatase treatment were prepared in $25 \mathrm{mmol} / \mathrm{l}$ Tris- $\mathrm{HCl}$ $\mathrm{pH} 7.4,2 \mathrm{mmol} / \mathrm{l}$ sodium orthovanadate, $0.5 \mathrm{mmol} / \mathrm{l}$ EGTA, $25 \mathrm{mmol} / \mathrm{l} \mathrm{NaCl}, 10 \mathrm{mmol} / 1 \mathrm{MgCl}_{2}$, and protease inhibitors [a 1:1000 dilution of protease inhibitor cocktail (Sigma P-8340)]. After three freeze-thaw cycles, the cells were centrifuged at $12000 \mathrm{~g}$ for $30 \mathrm{~min}$ at $4{ }^{\circ} \mathrm{C}$ and supernatant was collected. Aliquots $(300 \mu \mathrm{g})$ were incubated with 600 units of alkaline phosphatase (Sigma P3681) for $1 \mathrm{~h}$ at $37^{\circ} \mathrm{C}$. Following incubation, samples were boiled for $5 \mathrm{~min}$. in Laemmli sample buffer (50 mmol/1 Tris- $\mathrm{HCl}$ pH 6.8, 2\% SDS, $10 \%$ glycerol, $2 \%$ $\beta$-mercaptoethanol and $0.004 \%$ bromophenol blue), and separated by $7.5 \%$ SDS-PAGE .

Glucose transport. 2-Deoxyglucose (2DG) uptake measurements were performed as previously described [33].

Glycogen synthesis. Glycogen synthesis was measured, in 6-well plates, by assessing the amount of radioactivity in the glycogen fraction (precipitation in $70 \%$ ethanol) of cells incubated in the presence of $\left(\mathrm{U}-{ }^{14} \mathrm{C}\right)$ glucose. Following treatment cells were washed three times in PBS, and incubated with PBS containing $0.1 \mathrm{mmol} / \mathrm{l}\left(\mathrm{U}-{ }^{14} \mathrm{C}\right)$ glucose $(2 \mu \mathrm{Ci} /$ well $)$ in the absence or presence of $100 \mathrm{nmol} / \mathrm{l}$ insulin, for $1 \mathrm{~h}$. Cells were then washed, homogenized, and glycogen was precipitated on a Whatmann paper in $70 \%$ ethanol.

Statistical analysis. Data are expressed as means \pm standard error (SE). Each treatment was compared to control, and statistical significance between two groups was evaluated using the Student's $t$ test. A $p$ value of less than 0.05 was considered statistically significant.

\section{Results}

Oxidative stress induces decreased protein content and increased serine phosphorylation of IRS1. 3T3-L1 adipocytes and rat hepatoma FAO cells were exposed to stable $\mathrm{H}_{2} \mathrm{O}_{2}$ concentrations, generated by adding glucose oxidase to the culture medium. Cells were exposed for $2 \mathrm{~h}$ to $40 \pm 5 \mu \mathrm{mol} / 1 \mathrm{H}_{2} \mathrm{O}_{2}$, after which the cellular content of IRS proteins was evaluated in total cell lysates by Western blot analysis. For comparison, cells were treated for $5 \mathrm{~h}$ with $100 \mathrm{nmol} / \mathrm{l}$ insulin, conditions previously shown to decrease IRS1 protein content in the two cell lines. Exposure to $\mathrm{H}_{2} \mathrm{O}_{2}$ resulted in a reduction in IRS1 immunoreactivity in both 3T3-L1 adipocytes, as well as in FAO cells (Fig. 1A,B). This decreased expression level was associated with retarded migration of the IRS1 band in the SDS-polyacrylamide gel, an effect that was more pronounced in the FAO cells. Densitometry analysis of four independent experiments yielding similar results, showed that these conditions of oxidative stress resulted in $45 \pm 11$ and $37 \pm 5 \%$ decrease in IRS1 content in 3T3-L1 and FAO cells respectively, as compared to control cells $(p<0.05)$. As expected, 5-h exposure to $100 \mathrm{nmol} / \mathrm{l}$ insulin also resulted in a $40 \pm 9$ and $72 \pm 7 \%$ reduction in IRS1 content in $3 \mathrm{~T} 3-\mathrm{L} 1$ adipocytes and FAO, respectively, as well as a retarded gel migration of the IRS1 band in both cell types.
A
3 T3-L1
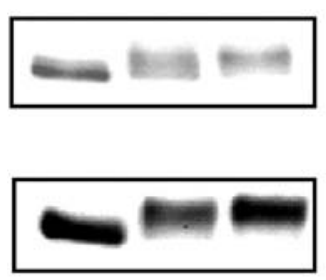

IB: anti IRS2

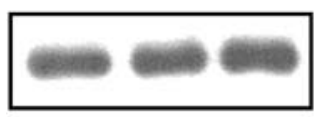

$\mathrm{C} \quad \mathrm{H}_{2} \mathrm{O}_{2}$ Ins

IB: anti P85
B

FAO
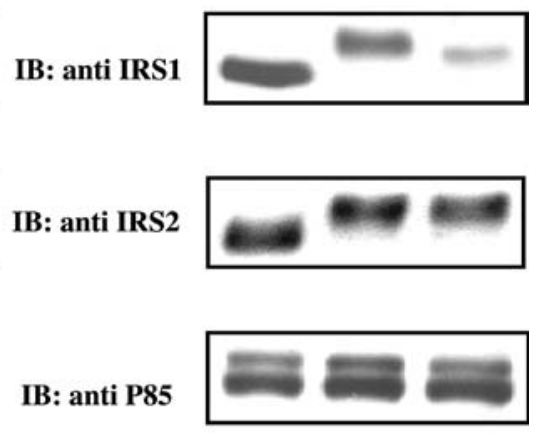

C $\mathrm{H}_{2} \mathrm{O}_{2}$ Ins
Fig. 1A, B. Effect of oxidative stress or prolonged insulin treatment on IRS1, IRS2 and PI 3-kinase in 3T3-L1 adipocytes and rat hepatoma Fao cells (FAO). Fully differentiated 3T3-L1 adipocytes (A) and FAO (B) cells were serum-starved for $16 \mathrm{~h}$ and treated with either glucose oxidase yielding a $40 \mu \mathrm{mol} / \mathrm{l}$ medium $\mathrm{H}_{2} \mathrm{O}_{2}$ concentration for $2 \mathrm{~h}\left(\mathrm{H}_{2} \mathrm{O}_{2}\right)$, or with $100 \mathrm{nmol} / \mathrm{l}$ insulin for $5 \mathrm{~h}$ (Ins). (C) represents control cells. Cells were then lysed, proteins were separated on 7.5\% SDS-PAGE, transferred and immunoblotted using the indicated antibodies. Shown are blots representative of four independent experiments yielding similar results

To assess whether the effect of oxidative stress on IRS1 content was associated with enhanced degradation of other insulin signalling proteins, cell lysates were analyzed for the protein level of both IRS2 and the p85 subunit of PI 3-kinase, representing a closely related as well as a structurally unrelated protein to IRS1, respectively. While affecting IRS2 migration in the gel, oxidative stress caused only a non-striking $12 \pm 2$ and $5 \pm 2 \%$ decrease in IRS 2 protein content in 3T3-L1 and FAO cells, respectively (Fig. 1). Similarly, 5-h exposure to insulin had only a minor effect on IRS 2 content in both cell types. The protein content of the p85 subunit of PI 3-kinase was unaltered by either oxidative stress or 5-h exposure to insulin (Fig. 1).

Since the decrease in IRS 1 content was associated with retarded migration of the band during SDS PAGE, we further addressed the possibility that oxidative stress resulted in increased Ser/Thr phosphorylation of IRS1. FAO cell lysates were prepared without Ser/Thr phosphatase inhibitors, and treated in vitro for $1 \mathrm{~h}$ in the absence or presence of alkaline phosphatatse, and analyzed for IRS1 gel retardation as before. Alkaline phosphatase treatment completely reversed the retarded migration of the IRS1 band that was induced by either oxidative stress or insulin (Fig. 2A). Importantly, the intensity of the IRS1 band was still decreased as compared to control following this in vitro treatment (being $64 \pm 7$ and $51 \pm 8 \%$ of control, in oxidized cells before and after alkaline phosphatase treatment). This verified that the decreased immunoreactivity of the IRS1 band following oxidative stress represented a true decrease in IRS1 content, and could 
A IB: anti IRS1

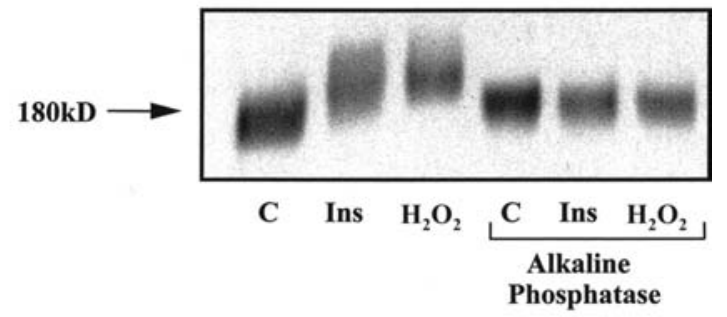

B IB: anti Phospho-Serine

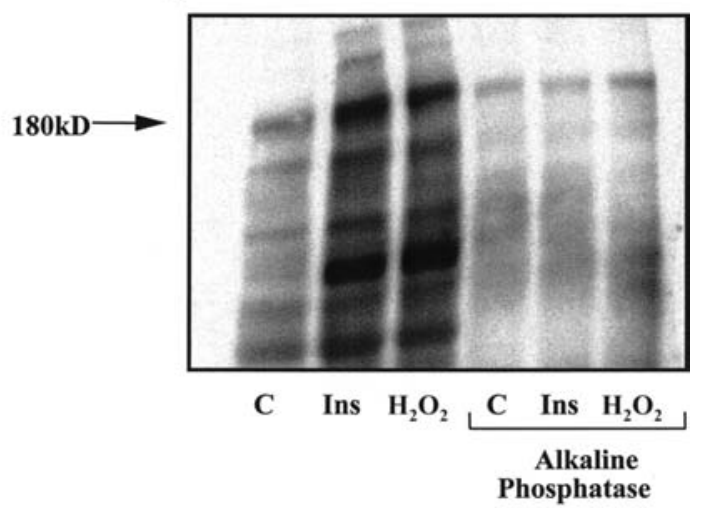

Fig. 2A, B. $\mathrm{H}_{2} \mathrm{O}_{2}$ and prolonged insulin treatment increase serine/threonine phosphorylation of IRS1. FAO cells were either incubated with no addition $(\mathbf{C})$, with glucose oxidase $\left(\mathrm{H}_{2} \mathrm{O}_{2}\right)$ or insulin (Ins). Cells were lysed in a lysis buffer devoid of Ser/Thr phosphatase inhibitors, and aliquots $(300 \mu \mathrm{g})$ were incubated without or with 600 units of alkaline phosphatase for $1 \mathrm{~h}$ at $37^{\circ} \mathrm{C}$, as described in Materials and Methods. Western blot analysis was performed using either IRS1 antibodies (A) or anti-phosphoserine antibodies (B). Shown are blots representative of four independent experiments yielding similar results

not be attributed to reduced affinity of the anti-IRS1 antibody to the serine/thronine hyper-phosphorylated IRS1 protein. To further establish that oxidative stress increased the serine phosphorylation of proteins in the cells, Western blot analysis of total cell lysates was carried out using anti phosphoserine antibodies. Lysates of cells exposed to oxidative stress exhibited an increased intensity of the signal generated with antiphosphoserine antibodies, an effect which was reversible by in vitro treatment of the lysates with alkaline phosphatase (Fig. 2B). Strikingly, increased serine phosphorylation of an approximate $180000 \mathrm{Mr}$ band was noticeable in response to oxidative stress, potentially corresponding to IRS protein(s). Yet, we were unable to show any visible band when IRS1 immunoprecipitates were blotted using the same antibody. Interestingly, chronic insulin stimulation also resulted in enhanced serine phosphorylation of proteins in total cell lysates, in a pattern that was similar to that obtained by oxidative stress. Collectively these data suggest that oxidative stress specifically decreased IRS1 protein content, and was associated with increased serine phosphorylation.
To better characterize the effect of oxidative stress on IRS1 content and serine phopshorylation, the time- and dose-dependencies of these effects were studied. A reduction in IRS1 content could be observed already after $2 \mathrm{~h}$ of exposure to $40 \pm 5 \mu \mathrm{mol} / \mathrm{l}$ $\mathrm{H}_{2} \mathrm{O}_{2}$ (Fig. 3A). A decrease in IRS1 content was observed after $2 \mathrm{~h}$ exposure to as low as $40 \mu \mathrm{mol} / \mathrm{l}$ $\mathrm{H}_{2} \mathrm{O}_{2}$ (Fig. 3B). In both experiments, the effect on IRS 1 serine phosphorylation, as evident by the retarded migration of the IRS1 band in the gel, coincided with the time and concentration change in IRS1 content.

Since the decrease in IRS1 content was induced after relatively short exposure to oxidative stress, we speculated that the major process underlying this phenomenon is enhancing protein degradation of IRS1. In order to exclude a major role for inhibition of translation of IRS1 transcripts, cells were exposed to oxidative stress in the presence of cycloheximide, an inhibitor of protein translation. The presence of $5 \mu \mathrm{g} / \mathrm{ml}$ cycloheximide for $2 \mathrm{~h}$ had no effect on IRS1 content in control cells, consistent with its half life of $20 \mathrm{~h}$. Moreover, it did not alter the decrease in IRS1 content induced by oxidative stress (Fig. 3C), supporting the notion that oxidative stress decreased IRS 1 content primarily by enhancing its protein degradation rate.

Oxidative stress-induced IRSI degradation is PI 3-kinase/mTOR dependent. As shown above, oxidative stress induced a decrease in IRS1 (but not IRS2) protein content similar to the effect of prolonged exposure to insulin. Recent studies on the induction of IRS1 degradation by prolonged insulin have shown the involvement of the PI 3-kinase/mTOR signalling pathway, but not the MEK-ERK1/2 pathway in IRS1 degradation. To assess whether oxidative stress utilized similar signalling pathways as chronic insulin in inducing IRS1 degradation, FAO cells were incubated with pharmacological inhibitors $15 \mathrm{~min}$. prior to, as well as during exposure to oxidative stress. Both LY294002, a PI 3-kinase inhibitor, as well as the mTOR inhibitor rapamycin, showed a similarly significant $(p<0.05)$, but not full capacity to protect against oxidative stress-induced IRS1 degradation (Fig. 4A). In contrast, no effect on IRS1 content and gel migration was noted using the MEK inhibitor PD98059. Identical results regarding the effect of the three inhibitors on IRS1 degradation were obtained in 3T3-L1 adipocytes (data not shown). Consistent with recent reports on insulin-mediated IRS1 degradation, the PI3-kinase inhibitor prevented both the decrease in IRS 1 content as well as its retarded migration in the gel (Fig. 4B). While rapamycin had a partial effect on insulin mediated IRS1 degradation, no similar effect was observed using PD98059. These data show the involvement of the PI 3-kinase/mTOR signalling pathway in mediating oxidative stress-induced IRS1 degradation and serine phosphorylation, similar but not 
A
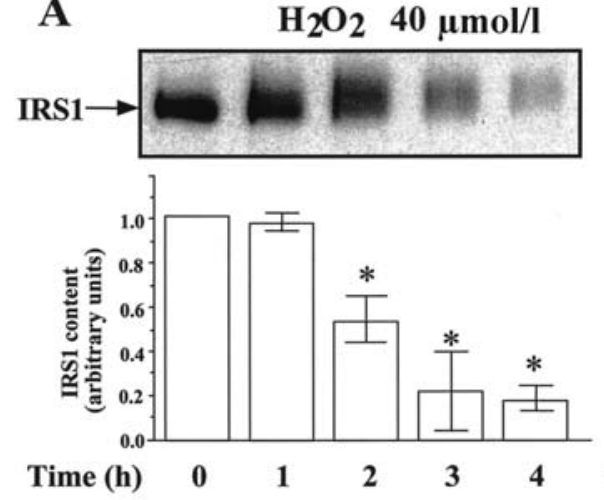

B

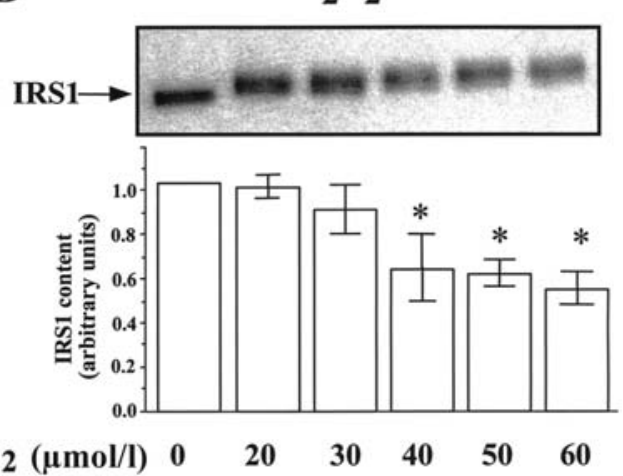

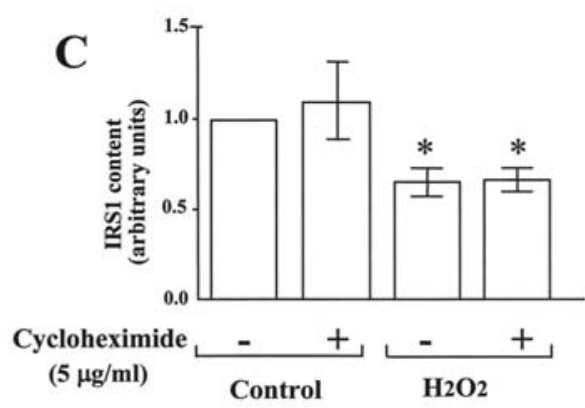

Fig. 3A-C. Time course and dose dependency of IRS1 changes induced by oxidative stress. (A) FAO cells were incubated with $100 \mathrm{mU} / \mathrm{ml}$ of glucose oxidase, which generated medium $\mathrm{H}_{2} \mathrm{O}_{2}$ concentrations of $40 \pm 5 \mu \mathrm{mol} / 1 \mathrm{H}_{2} \mathrm{O}_{2}$ for the indicated time periods. (B) Cells were exposed to various glucose oxidase concentrations yielding the indicated medium $\mathrm{H}_{2} \mathrm{O}_{2}$ concentrations for $2 \mathrm{~h}$. (C) Cells were incubated for $15 \mathrm{~min}$ prior

A
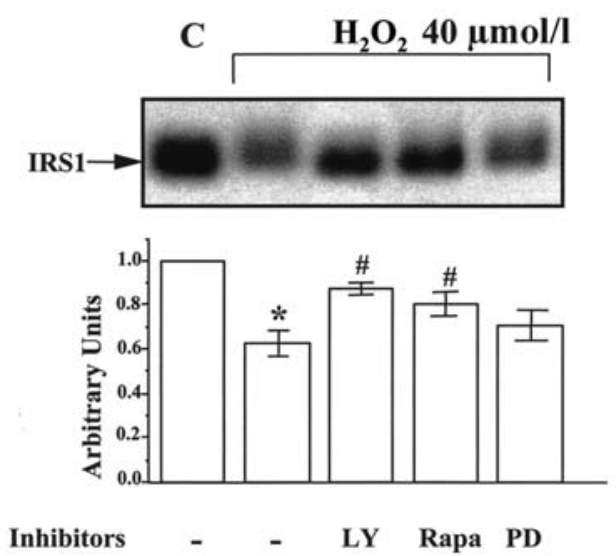

Fig. 4A, B. Effect of PI3-kinase, mTOR and MEK inhibitors on IRS 1 changes induced by $\mathrm{H}_{2} \mathrm{O}_{2}$ or prolonged insulin. FAO cells were pretreated for $15 \mathrm{~min}$ prior to and then during glucose oxidase $\left(\mathrm{H}_{2} \mathrm{O}_{2}\right),(\mathbf{A})$ or insulin treatment $(\mathbf{B})$, with either vehicle (DMSO final concentration of $0.2 \%, \mathrm{C}$ ), $100 \mu \mathrm{mol} / \mathrm{l}$ LY294002 (LY), $150 \mathrm{nmol} / \mathrm{l}$ Rapamycin (Rapa), or $50 \mu \mathrm{mol} / 1$ PD98059 (PD). Cells were then analyzed for IRS1 by Western blot analysis. Shown are representative blots as well as the results of densitometry analysis of three independent experiments, in which a value of 1 was assigned for IRS 1 band intensity in control cells. $* p<0.05$ as compared to control cells. $\# p<0.05$ as compared to treated cells without inhibitors to and during exposure to $\mathrm{H}_{2} \mathrm{O}_{2}$ without or with $5 \mu \mathrm{g} / \mathrm{ml}$ cycloheximide, a protein synthesis inhibitor. Following each of these experiments, cell lysates were prepared and analyzed for IRS1. Shown are representative blots (for A and B), as well as the results of densitometry analysis of three independent experiments, in which a value of 1 was assigned for IRS1 band intensity in control cells. $* p<0.05$ as compared to control cells

B

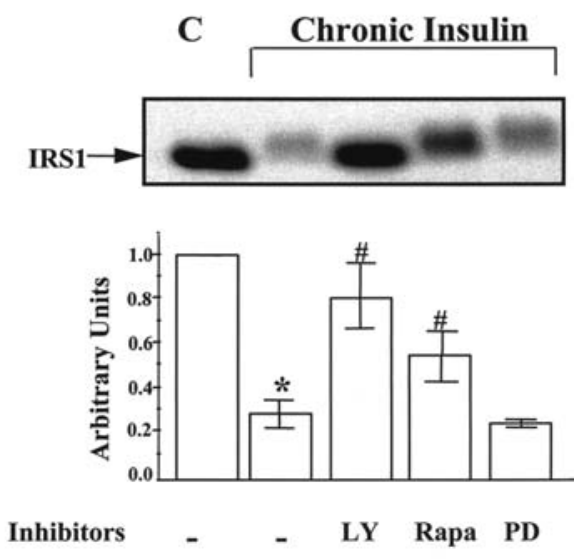

identical to their involvement in IRS1 degradation induced by chronic insulin.

The role of the ubiquitin-proteasome system in IRS1 degradation following oxidative stress. Since protein degradation occurs in the cell through several pathways, the most prominent of which is the protein ubiquitination-proteasome pathway, we next assessed its involvement in the protein degradation of IRS1 induced by oxidative stress. Using immunodetection 
A

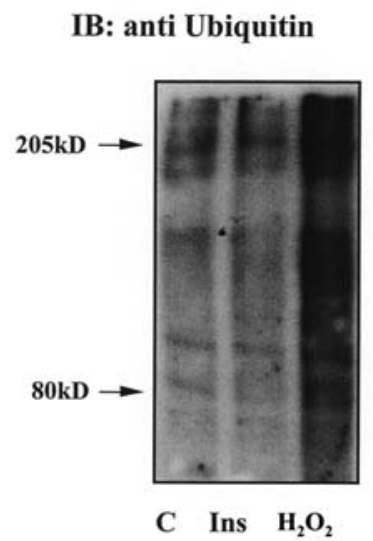

Fig. 5A, B. The involvement of the ubiquitin-proteasome system in IRS1 degradation induced by oxidative stress or prolonged insulin. FAO cells were exposed to prolonged insulin (Ins) or $\mathrm{H}_{2} \mathrm{O}_{2}$ generated by glucose oxidase $\left(\mathrm{H}_{2} \mathrm{O}_{2}\right)$. Total cell lysates were separated on SDS-PAGE and blotted with antiubiquitin antibodies (A). FAO cells were incubated for $15 \mathrm{~min}$ prior to and during insulin or $\mathrm{H}_{2} \mathrm{O}_{2}$ treatment with $10 \mu \mathrm{mol} / \mathrm{l}$ lactacystin or vehicle (DMSO, final concentration $0.2 \%$ ) $(\mathbf{B}, \mathbf{C})$. IRS 1 content in total cell lyastes was assessed by Western blot analysis. Shown are blots representative of three independent experiments yielding similar results

with anti-ubiquitine antibody, lysates of cells exposed to oxidative stress displayed increased total protein ubiquitination (Fig. 5A). This effect was not observed in lysates of cells exposed for $5 \mathrm{~h}$ to $100 \mathrm{nmol} / \mathrm{l}$ insulin. However, we could not detect a band when IRS1 was immunoprecipitated and blotted using the same anti-ubiquitine antibody (not shown). Addition of the proteasome inhibitor lactacystin could not prevent the decrease in IRS1 content (Fig. 5B), suggesting a lack of involvement of the proteasome protein degradation pathway in decreasing IRS1 content following oxidative stress. In contrast, lactacystin fully prevented IRS1 degradation when induced by insulin (Fig. 5C), consistent with recent reports. To exclude the possibility that the $\mathrm{H}_{2} \mathrm{O}_{2}$ decreased the bio-activity of lactacystin resulting in lack of effect in the cells coexposed to oxidative stress, lactacystin was incubated for $2 \mathrm{~h}$ with $40 \mu \mathrm{mol} / 1 \mathrm{H}_{2} \mathrm{O}_{2}$. Catalase was then added to hydrolyse remaining $\mathrm{H}_{2} \mathrm{O}_{2}$, and the lactacystin containing medium was assessed for its capacity to inhibit IRS1 degradation by 5 -h exposure to insulin. The effect of the lactacystin exposed to $\mathrm{H}_{2} \mathrm{O}_{2}$ was identical to fresh lactacystin added to the medium (data not shown). Collectively, these data confirm the bioactivity of lactacystin in these experiments. Similar results to those obtained with lactacystin were observed when using an alternative proteasome inhibitor, MG132. MG132 did not prevent oxidative stress-induced IRS1 degradation, while it prevented its degradation by chronic insulin exposure. Taken together these
B

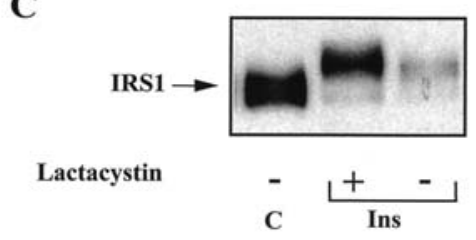

data argue against a role for the proteasome pathway in IRS1 degradation induced by oxidative stress, despite the observed increase in total protein ubiquitination.

The effect of IRS1 modifications by oxidative stress on insulin-mediated signalling and metabolism. We next assessed the effect of the alterations in IRS1 induced by oxidative stress on its capacity to bind PI 3-kinase in response to acute insulin stimulation. FAO cells were treated for $3 \mathrm{~h}$ with $\mathrm{H}_{2} \mathrm{O}_{2}$ or for $4 \mathrm{~h}$ with $100 \mathrm{nmol} / \mathrm{l}$ insulin, washed, and subsequently stimulated for 1 min with $100 \mathrm{nmol} / \mathrm{l}$ insulin. IRS1 was immunoprecipitated from total cell lysates, and immunopreciptates subjected to Western blot analysis. In non-oxidized cells, acute insulin stimulation induced an increase in the p85 regulatory subunit of PI 3-kinase that co-precipitated with IRS1 (Fig. 6A). Both chronic insulin as well as oxidative stress decreased the amount of $\mathrm{p} 85$ associated with IRS1 following acute insulin stimulation. Densitometry analysis showed a $52 \pm 2$ and $48 \pm 3 \%$ decrease in the amount of p85 in the immunoprecipitates in oxidized and chronic insulin treated cells, respectively. The same blots were analyzed for the amount of IRS1 that was precipitated. Oxidative stress and chronic insulin treatments resulted in a $42 \pm 5$ and $58 \pm 12 \%$ decrease in the amount of IRS1 immunoprecipitated from lysates (Fig. 6B), in agreement with the changes observed in total cell lysates (Fig. 1B). Thus, the decrease in p85 that co-precipitated with IRS1 (Fig. 6A) closely matched the reduction in cellular IRS1 content (Fig. 6B). Interestingly, under the same conditions, acute insulin-stimulated PKB/Akt serine 473 phosphorylation was almost completely blunted in cells exposed to oxidative stress (Fig. 6C), exceeding the effect observed on IRS1 content and interaction with $\mathrm{p} 85$. This finding suggests that the severity of the signalling defect induced by oxidative stress increases with down-stream propagation of the signal, or that the changes observed in IRS1 do not represent the actual rate-limiting step functionally responsible for im- 
A

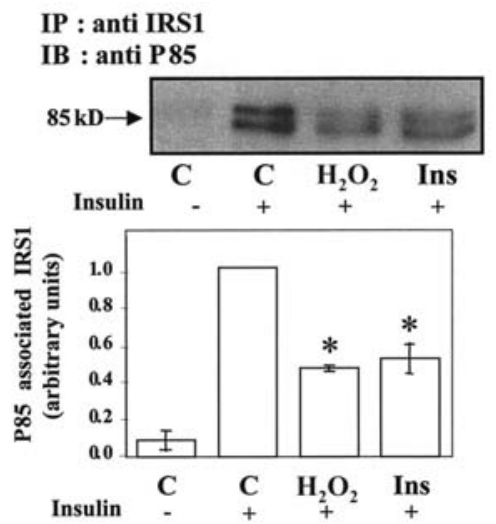

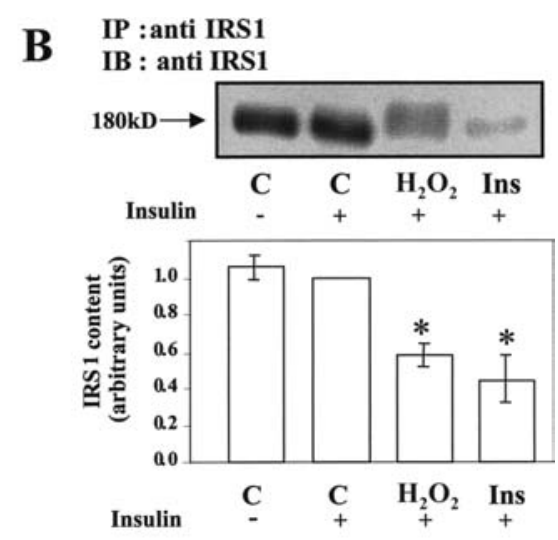
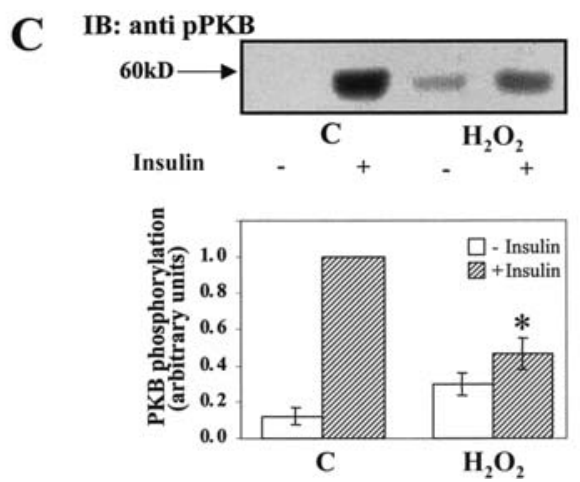

Fig. 6A-C. The effect of oxidative stress on the association of IRS1 with P85, and on PKB phosphorylation induced by acute insulin stimulation. FAO cells were treated with glucose oxidase $\left(\mathrm{H}_{2} \mathrm{O}_{2}\right)$ for $3 \mathrm{~h}$ or $100 \mathrm{nmol} / \mathrm{l}$ insulin for $4 \mathrm{~h}$, after which the cells were washed and further incubated for $1 \mathrm{~min}$ in the absence or presence of $100 \mathrm{nmol} / \mathrm{l}$ insulin. The cells were washed, lysed and IRS1 was immunoprecipitate from $500 \mu \mathrm{g}$ protein and analyzed by Western blot using either the regulatory subunit of PI3 kinase (P85) (A), or IRS1 antibodies (B). In (C) lysates of control and oxidized cells were analyzed by Western blot using phospho-specific PKB antibody. Shown are blots representing four independent experiments as well as the results of densitometry analysis, in which a value of 1 unit was set to represent the content of either P85 (A), IRS1 (B) or pPKB (C) in non-oxidized cells in the presence of insulin. $* p<0.05$ compared with non-oxidized cells in the presence of insulin.

paired metabolic responses to insulin. To verify the latter possibility, we assessed whether changes in IRS1 induced by oxidative stress correlate with impaired metabolic response to acute insulin stimulation, using two complementary approaches. Firstly, we evaluated whether protecting against IRS1 degradation and serine phosphorylation induced by oxidative stress using rapamycin (Fig. 4A), would result in improved insulin mediated glycogen synthesis in FAO cells or insulin-stimulated glucose uptake in 3T3-L1 adipocytes. In FAO cells insulin increased glucose incorporation to glycogen, while oxidative stress blunted this effect (Fig. 7A). Surprisingly, while rapamycin protected against IRS1 degradation and serine phosphorylation (Fig. 4A), this was not associated with im- proved response to acute insulin stimulation (Fig. 7A). In 3T3-L1 adipocytes, exposure to $\mathrm{H}_{2} \mathrm{O}_{2}$ reduced insulin-stimulated glucose transport. Incubation with rapamycin, though preventing oxidative stress-induced IRS1 alterations, had no effect on the reduction of insulin-stimulated glucose transport (data not shown). Secondly, we evaluated whether preincubation with the antioxidant lipoic acid protected against IRS1 serine phosphorylation and degradation. 3T3-L1 adipocytes were pre-treated for $16 \mathrm{~h}$ with $200 \mu \mathrm{mol} / \mathrm{l}$ alpha lipoic acid, washed, and exposed for $2 \mathrm{~h}$ to oxidative stress. Using this protocol, lipoic acid pre-treatment prevented oxidative stress-induced reduction in insulin-stimulated glucose uptake and PKB phosphorylation (Fig. 7B). Yet, this was not associated with a protection against IRS1 degradation or increased serine phosphorylation (Fig. 7C). Densitometry analysis showed a $55 \pm 11$ and $65 \pm 7 \%$ of control in oxidized cells in the absence or presence of lipoic acid, respectively. Collectively, these data suggest that the reduction in IRS1 content and/or its increased serine phosphorylation induced by oxidative stress cannot fully predict the degree of impairment in the metabolic response to insulin, nor the protective effect provided by an antioxidant.

\section{Discussion}

This study provides evidence that oxidative stress, concomitant to its ability to induce metabolic insulin resistance, also increases IRS1 serine phosphoryla- 


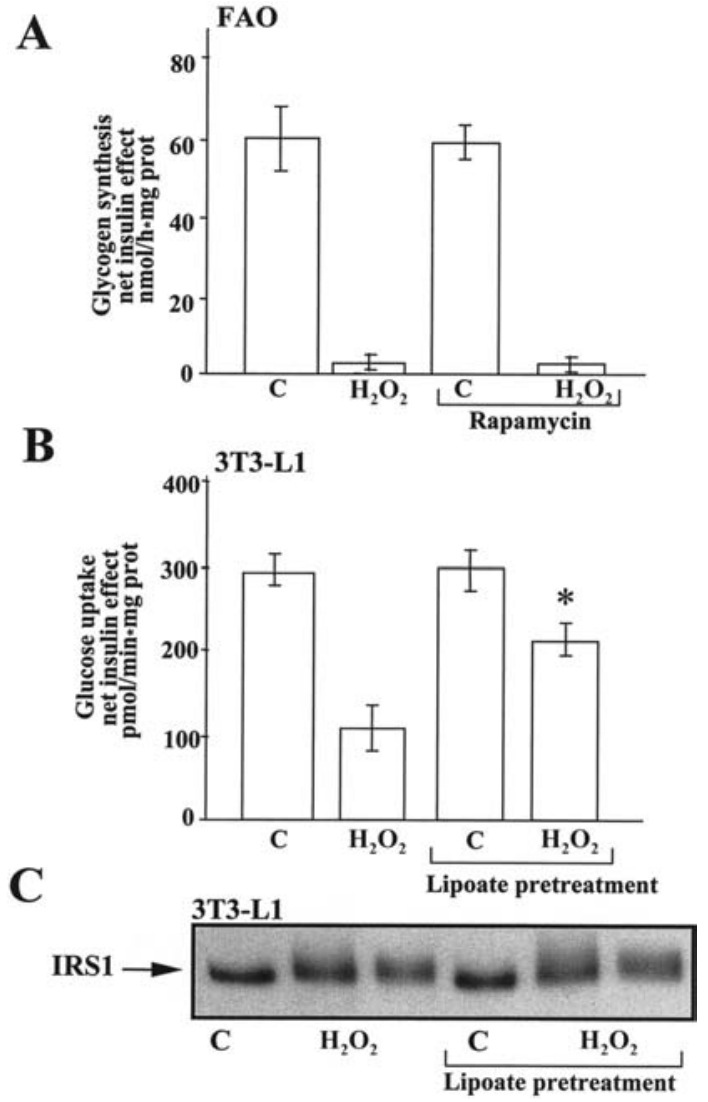

Fig. 7A-C. Different effects on oxidative stress-induced IRS1 changes and on the impaired metabolic response to insulin by rapamycin and alpha lipoic acid. (A) FAO cells were pretreated with $150 \mathrm{nmol} / 1$ rapamycin for $15 \mathrm{~min}$ prior to and during the treatment with $\mathrm{H}_{2} \mathrm{O}_{2}$ generated by glucose oxidase $\left(\mathrm{H}_{2} \mathrm{O}_{2}\right)$. Incorporation of radiolabel glucose to glycogen in the absence or presence of insulin was measured. (B) 3T3-L1 adipocytes were treated for $16 \mathrm{~h}$ in serum-free (BSA supplemented) medium without or with $200 \mu \mathrm{mol} / 1$ racemic alpha lipoic acid, after which cells were washed and incubated for $2 \mathrm{~h}$ with $\mathrm{H}_{2} \mathrm{O}_{2}$. Thereafter cells were washed, and glucose uptake was measured without and after exposed for $20 \mathrm{~min}$ to $100 \mathrm{nmol} / \mathrm{l}$ insulin. The results (in $\mathbf{A}$ and $\mathbf{B}$ ) represent the mean \pm SE of five independent experiments. ${ }^{*} p<0.05$ compared with net insulin effect in oxidized cells. (C) 3T3-L1 adipocytes were pre-treated with lipoic acid and exposed to $\mathrm{H}_{2} \mathrm{O}_{2}$, after which IRS1 content was evaluated by Western blot. Shown is a blot representing two additional experiments yielding similar results.

tion, and enhances its protein degradation in 3T3-L1 adipocytes and FAO cells. Both effects are sensitive to LY294002 and rapamycin (but not to PD98509), suggesting the involvement of a PI 3-kinase and/or mTOR dependent mechanism, respectively. In contrast to changes induced by prolonged exposure to insulin, the degradation of IRS1 was insensitive to proteasome inhibitors, despite an overall increase in cellular protein ubiquitination.

Both $\mathrm{H}_{2} \mathrm{O}_{2}$ and chronic exposure to insulin resulted in increased IRS1 serine phosphorylation. The mechanisms by which both conditions induce IRS 1 serine phosphorylation are similar, but not identical. In both cases, an inhibitor of PI 3-kinase or of mTOR, but not of MEK1, prevented IRS1 changes suggesting that oxidative stress might activate components of the insulin signalling cascade (insulin mimicking effect) as was shown to occur with milimolar $\mathrm{H}_{2} \mathrm{O}_{2}$ [34]. Consistent with this notion is the finding, that both oxidative stress and chronic insulin had a differential effect on IRS1 compared with IRS2: while IRS1 protein content was largely decreased, IRS2 was relatively resistant to enhanced protein degradation $[18,30]$. However, the magnitude of the inhibitory effect of each inhibitor differed: while in the case of prolonged insulin rapamycin had about $50 \%$ the potency in inhibiting IRS1 changes compared with LY29002, the two agents had a similar effect following oxidative stress. This could reflect a difference in the relative input of the various kinases involved. The serine phosphorylation and degradation of IRS1 following chronic insulin might be mediated directly by the serine kinase activity of the p110 subunit of PI 3-kinase [18, 19, 35]. In the case of oxidative stress, it seems that most of the input from PI 3-kinase is mediated by kinase(s) also inhibited by rapamycin such as p70 S6 kinase. Yet, neither rapamycin nor LY29002 completely prevented the reduction in IRS1 content following oxidative stress. This finding suggests that oxidative stress also affected IRS1 through input from additional kinases that are resistant to these inhibitors. Potential candidates include JNK and IKKbeta, both of which have been reported to be activated by oxidative stress, and have been implicated in phosphorylating IRS1 on Ser/Thr residues [4, 36, 37]. Different balance between kinases might result in a different set of phosphorylated Ser/Thr residues on IRS1 molecules, resulting in susceptibility to distinct degradation pathways. Indeed, our data suggests different contributions of the proteasome system in the enhanced protein degradation of IRS1 following oxidative stress compared with chronic insulin. While, as previously reported [17, 18, 19], chronic insulin-induced IRS1 degradation was inhibitable by two distinct inhibitors of the proteasome, oxidative stress-induced degradation was resistant to these agents. Several potential mechanisms could account for this difference. Assuming that under both conditions IRS1 becomes ubiquitinated, chronic insulin and oxidative stress might result in different lengths of the poly-ubiquitin chain. It seems that multiubiquitin chains are essential for proteolytic targeting, whereas mono-ubiquitination might only affect sub-cellular localization [38]. Alternatively, it is possible that oxidative stress inhibits proteasomal activity. Indeed, oxidative stress was previously shown to exert a bi-modal effect on the proteasomal degradation of cellular proteins, with enhanced proteasomal degradation at the early phase and a subsequent inhibition of the 26 subunit of the proteasome, resulting in accumulation of ubiquitinated proteins [39]. Supporting this notion is the finding that oxidative stress resulted in a 
striking increase in total protein ubiquitination. Under these circumstances, other protein degradation systems that are less vulnerable to oxidative damage could predominate in degrading IRS1. These might include lysosomal proteases or Ca-dependent proteases, which were also previously suggested to participate in IRS1 degradation [40]. Thus, the protease involved in IRS1 degradation in response to oxidative stress has yet to be identified.

The role of IRS1 serine phosphorylation and degradation induced by oxidation in determining the metabolic response to acute insulin stimulation is questionable. In 3T3-L1 adipocyte, protection against oxidation-induced impairment in insulin-stimulated glucose uptake and PKB phosphorylation by lipoic acid pretreatment, had no similar protective effect on IRS1 content or serine phosphorylation [41]. Moreover, in FAO cells, rapamycin co-treatment, which prevented IRS1 changes induced by oxidative stress, could not protect the impairment in insulin-stimulated glycogen synthesis. Redundancy in IRS1 function had been documented in skeletal muscle of insulin resistant patients, in which a $50 \%$ decrease in insulin-stimulated IRS1-associated PI3-kinase activity did not manifest in impaired activation of PKB [42]. In this study, however, $\mathrm{PKB} / \mathrm{Akt}$ phosphorylation in response to acute insulin stimulation was strikingly impaired, to a degree that exceeded the decrease in $\mathrm{p} 85$ that associated with IRS1. Previous studies have suggested that impaired sub-cellular localization of IRS1 and PI 3-kinase that were induced by oxidative stress, could contribute to impaired PKB/Akt activation by insulin, and to metabolic insulin resistance [7]. Our results suggest that at least in response to oxidative stress, alterations in the IRS1 protein itself cannot fully predict either the degree of decrease in $\mathrm{PKB} / \mathrm{Akt}$ phosphorylation or the impaired metabolic response to insulin, in both 3T3-L1 adipocytes and FAO cells. These results suggest that signalling step(s) downstream of IRS1 become rate-limiting in the induction of metabolic insulin resistance by oxidative stress.

In conclusion, oxidative stress elicits serine phosphorylation of IRS1 and enhances its protein degradation, similar to prolonged insulin and other inducers of cellular insulin resistance. Yet, contrary to prolonged insulin, this process cannot be prevented by inhibitors of the proteasome degradation machinery. Defining the functional importance of these alterations in IRS1 that are induced by oxidative stress for the occurrence of impaired metabolic response to insulin remains pivotal for distinguishing an association compared with a causative relationship between the two.

Acknowledgements. We would like to thank Dr A. Klip for helpful comments during the preparation of this manuscript. We acknowledge the technical assistance of E. Malyarevskaya. This work was supported by a grant from the Israeli Ministry of Health.

\section{References}

1. Rudich A, Tirosh A, Potashnik R, Hemi R, Kanety H, Bashan N (1998) Prolonged oxidative stress impairs insulin-induced GLUT4 translocation in 3T3-L1 adipocytes. Diabetes 47:1562-1569

2. Tirosh A, Rudich A, Potashnik R, Bashan N (2001) Oxidative stress impairs insulin but not platelet-derived growth factor signalling in 3T3-L1 adipocytes. Biochem J 355:757763

3. Blair AS, Hajduch E, Litherland GJ, Hundal HS (1999) Regulation of glucose transport and glycogen synthesis in L6 muscle cells during oxidative stress. Evidence for cross-talk between the insulin and SAPK2/p38 mitogenactivated protein kinase signaling pathways. J Biol Chem 274:36293-36299

4. Evans JL, Goldfine ID, Maddux BA, Grodsky GM (2002) Oxidative stress and stress-activated signaling pathways: a unifying hypothesis of type 2 diabetes. Endocr Rev 23:599-622

5. Pessler D, Rudich A, Bashan N (2001) Oxidative stress impairs nuclear proteins binding to the insulin responsive element in the GLUT4 promoter. Diabetologia 44:2156-2164

6. Lockwood TD (2000) Redox control of protein degradation. Antioxid Redox Signal 2:851-878

7. Tirosh A, Potashnik R, Bashan N, Rudich A (1999) Oxidative stress disrupts insulin-induced cellular redistribution of insulin receptor substrate-1 and phosphatidylinositol 3-kinase in 3T3- L1 adipocytes. A putative cellular mechanism for impaired protein kinase B activation and GLUT4 translocation. J Biol Chem 274:10595-10602

8. White MF (1998) The IRS-signalling system: a network of docking proteins that mediate insulin action. Mol Cell Biochem 182:3-11

9. Virkamaki A, Ueki K, Kahn CR (1999) Protein-protein interaction in insulin signaling and molecular mechanisms of insulin resistance. J Clin Invest 103:1519-1529

10. Rondinone CM, Wang LM, Lonnroth P, Wesslau C, Pierce JH, Smith U (1997) Insulin receptor substrate (IRS) 1 is reduced and IRS-2 is the main docking protein for phosphatidylinositol 3-kinase in adipocytes from subjects with noninsulin-dependent diabetes mellitus. Proc Natl Acad Sci USA 94:4171-4175

11. Carvalho E, Jansson PA, Axelsen M et al. (1999) Low cellular IRS 1 gene and protein expression predict insulin resistance and NIDDM. FASEB J 13:2173-2178

12. Cusi K, Maezono K, Osman A et al. (2000) Insulin resistance differentially affects the PI 3-kinase- and MAP kinase-mediated signaling in human muscle. J Clin Invest 105:311-320

13. Storgaard H, Song XM, Jensen CB et al. (2001) Insulin signal transduction in skeletal muscle from glucose-intolerant relatives of type 2 diabetic patients. Diabetes 50:2770-2778

14. Rice KM, Turnbow MA, Garner CW (1993) Insulin stimulates the degradation of IRS-1 in 3T3-L1 adipocytes. Biochem Biophys Res Commun 190:961-967

15. Saad MJ, Folli F, Kahn CR (1995) Insulin and dexamethasone regulate insulin receptors, insulin receptor substrate-1, and phosphatidylinositol 3-kinase in Fao hepatoma cells. Endocrinology 136:1579-1588

16. Stephens JM, Lee J, Pilch PF (1997) Tumor necrosis factor-alpha-induced insulin resistance in 3T3-L1 adipocytes is accompanied by a loss of insulin receptor substrate- 1 and GLUT4 expression without a loss of insulin receptor-mediated signal transduction. J Biol Chem 272:971-976 
17. Sun XJ, Goldberg JL, Qiao LY, Mitchell JJ (1999) Insulininduced insulin receptor substrate-1 degradation is mediated by the proteasome degradation pathway. Diabetes 48:1359-1364

18. Haruta T, Uno T, Kawahara J et al. (2000) A rapamycinsensitive pathway down-regulates insulin signaling via phosphorylation and proteasomal degradation of insulin receptor substrate-1. Mol Endocrinol 14:783-794

19. Zhande R, Mitchell JJ, Wu J, Sun XJ (2002) Molecular mechanism of insulin-induced degradation of insulin receptor substrate 1. Mol Cell Biol 22:1016-1026

20. Rui L, Fisher TL, Thomas J, White MF (2001) Regulation of insulin/insulin-like growth factor-1 signaling by proteasome-mediated degradation of insulin receptor substrate-2. J Biol Chem 276:40362-40367

21. Ciechanover A, Schwartz AL (1998) The ubiquitin-proteasome pathway: the complexity and myriad functions of proteins death. Proc Natl Acad Sci USA 95:2727-2730

22. Zick Y (2001) Insulin resistance: a phosphorylation-based uncoupling of insulin signaling. Trends Cell Biol 11:437-441

23. Paz K, Liu YF, Shorer H et al. (1999) Phosphorylation of insulin receptor substrate-1 (IRS-1) by protein kinase B positively regulates IRS-1 function. J Biol Chem 274:28816-28822

24. Ravichandran LV, Esposito DL, Chen J, Quon MJ (2001) Protein kinase C-zeta phosphorylates insulin receptor substrate-1 and impairs its ability to activate phosphoatidylinositol 3-kinase in response to insulin. J Biol Chem 276:3543-3549

25. De Fea K, Roth RA (1997) Modulation of insulin receptor substrate- 1 tyrosine phosphorylation and function by mitogen-activated protein kinase. J Biol Chem 272:3140031406

26. Eldar-Finkelman H, Krebs EG (1997) Phosphorylation of insulin receptor substrate 1 by glycogen synthase kinase 3 impairs insulin action. Proc Natl Acad Sci USA 94:9660-9664

27. Aguirre V, Uchida T, Yenush L, Davis R, White MF (2000) The c-Jun NH(2)-terminal kinase promotes insulin resistance during association with insulin receptor substrate-1 and phosphorylation of Ser(307). J Biol Chem 275:90479054

28. Tanti JF, Germeaux T, Van Obberghen E, Le MarchandBrustel Y (1994) Insulin receptor substrate 1 is phosphorylated by the serine kinase activity of phosphatidylinositol 3-kinase. Biochem J 304:17-21

29. Aguirre V, Werner ED, Giraud J, Lee YH, Shoelson SE, White MF (2002) Phosphorylation of Ser307 in insulin receptor substrate-1 blocks interactions with the insulin receptor and inhibits insulin action. J Biol Chem 277:1531-1537
30. Pederson TM, Kramer DL, Rondinone CM (2001) Serine/threonine phosphorylation of IRS-1 triggers its degradation: possible regulation by tyrosine phosphorylation. Diabetes 50:24-31

31. Clark SF, Molero JC, James DE (2000) Release of insulin receptor substrate proteins from an intracellular complex coincides with the development of insulin resistance. J Biol Chem 275:3819-3826

32. Thurman RG, Ley HG, Scholz R (1972) Hepatic microsomal ethanol oxidation. Hydrogen peroxide formation and the role of catalase. Eur J Biochem 25:420-430

33. Rudich A, Kozlovsky N, Potashnik R, Bashan N (1997) Oxidant stress reduces insulin responsiveness in 3T3-L1 adipocytes. Am J Physiol 272:E935-940

34. Heffetz D, Bushkin I, Dror R, Zick Y (1990) The insulinomimetic agents $\mathrm{H}_{2} \mathrm{O}_{2}$ and vanadate stimulate protein tyrosine phosphorylation in intact cells. $\mathrm{J}$ Biol Chem 265:2896-2902

35. Egawa K, Nakashima N, Sharma PM et al. (2000) Persistent activation of phosphatidylinositol 3-kinase causes insulin resistance due to accelerated insulin-induced insulin receptor substrate-1 degradation in 3T3-L1 adipocytes. Endocrinology 141:1930-1935

36. Lee YH, Giraud J, Davis RJ, White MF (2003) cJUN $\mathrm{N}$-terminal kinase (JNK) mediates feedback inhibition of the insulin signaling cascade. J Biol Chem. 278:28962902

37. Gao Z, Hwang D, Bataille F et al. (2002) Serine phosphorylation of insulin receptor substrate 1 by inhibitor kappa $B$ kinase complex. J Biol Chem 277:48115-48121

38. Beal R, Deveraux Q, Xia G, Rechsteiner M, Pickart C (1996) Surface hydrophobic residues of multiubiquitin chains essential for proteolytic targeting. Proc Natl Acad Sci USA 93:861-866

39. Shang F, Gong X, Taylor A (1997) Activity of ubiquitindependent pathway in response to oxidative stress. Ubiquitin-activating enzyme is transiently up-regulated. J Biol Chem 272:23086-23093

40. Smith LK, Rice KM, Garner CW (1996) The insulin-induced down-regulation of IRS-1 in 3T3-L1 adipocytes is mediated by a calcium-dependent thiol protease. Mol Cell Endocrinol 122:81-92

41. Rudich A, Tirosh A, Potashnik R, Khamaisi M, Bashan N (1999) Lipoic acid protects against oxidative stress induced impairment in insulin stimulation of protein kinase B and glucose transport in 3T3-L1 adipocytes. Diabetologia 42:949-957

42. Kim YB, Nikoulina SE, Ciaraldi TP, Henry RR, Kahn BB (1999) Normal insulin-dependent activation of Akt/protein kinase $\mathrm{B}$, with diminished activation of phosphoinositide 3-kinase, in muscle in type 2 diabetes. J Clin Invest 104:733-741 